\title{
Modeling the Snowmelt Runoff Process of the Tizinafu River Basin, Northwest China, with GLDAS Data and Bayesian Uncertainty Analysis $\mathscr{O}$
}

\author{
Wenyi Xie, ${ }^{a}$ Xiankui Zeng, ${ }^{\mathrm{a}}$ Dongwei Gui, ${ }^{\mathrm{b}}$ Jichun Wu, ${ }^{\mathrm{a}}$ And Dong Wang ${ }^{\mathrm{a}}$ \\ ${ }^{\text {a }}$ Key Laboratory of Surficial Geochemistry, Ministry of Education, School of Earth Sciences and Engineering, Nanjing University, \\ Nanjing, China \\ ${ }^{\mathrm{b}}$ Cele National Station of Observation and Research for Desert-Grassland Ecosystem, Xinjiang Institute of Ecology and Geography, \\ Chinese Academy of Sciences, Urumqi, China
}

(Manuscript received 30 June 2020, in final form 29 October 2020)

\begin{abstract}
The climate of the Tizinafu River basin is characterized by low temperature and sparse precipitation, and snow and glacier melt serve as the main water resource in this area. Modeling the snowmelt runoff process has great significance for local ecosystems and residents. The total streamflow of the Tizinafu River basin was divided into surface streamflow and baseflow. The surface streamflow was estimated using the routing model (RM) with Noah runoff data from Global Land Data Assimilation (GLDAS), and the parameter uncertainty of the RM was quantified through Markov chain Monte Carlo simulation. Additionally, the 10 commonly used baseflow separation methods of four categories [digital filter, hydrograph separation program (HYSEP), baseflow index, and Kalinlin methods] were used to generate the baseflow and were then evaluated by their performance in total streamflow simulation. The results demonstrated that the RM driven by GLDAS runoff data could reproduce the runoff process of the Tizinafu River basin. RM-Hl (local minimum HYSEP method) achieved the best performance in the total streamflow simulation, with Nash-Sutcliffe efficiency (NSE) coefficients of 0.82 and 0.93 , relative errors of $-0.40 \%$ and $10.50 \%$, and observation inclusion ratios $C$ of $62.07 \%$ and $68.52 \%$ for the calibration and verification periods, respectively. The local minimum HYSEP method was most suitable for describing the baseflow of the Tizinafu River basin among the 10 baseflow separation methods. However, digital filter methods exhibited weak performance in baseflow separation.
\end{abstract}

KEYWORDS: Bayesian methods; Hydrologic models; Model evaluation/performance

\section{Introduction}

In the arid land of northwestern China, production activities and lives are greatly affected by the allocation of water resources. As the major water source of rivers, ice and snow meltwater from the cold and arid mountain areas greatly impacts the availability of water resources. Therefore, snowmelt runoff modeling and prediction are necessary for water resource management in cold and arid areas. The Tizinafu River basin is located at the central part of Eurasia in southwestern China, and is a typical arid and cold area with extremely low temperature and scarce precipitation. Snow and glacier meltwater provide most of the total river flow of Tizinafu River (Liston and Elder 2006; Marsh 1999), and also provides water to approximately two million inhabitants while maintaining a fragile ecological environment. Therefore, a reliable simulation of snowmelt runoff is important for local economic development and the ecosystem, and is also the main research motivation of this study.

Snowmelt can affect regional climate, ecosystems, and hydrology (Yang et al. 2003). Some researchers demonstrated that the snowmelt period has begun to start earlier in recent decades, together with winter and spring warming (Lammers

Supplemental information related to this paper is available at the Journals Online website: https://doi.org/10.1175/JHM-D-200162.s1.

Corresponding author: Xiankui Zeng, xiankuizeng@nju.edu.cn et al. 2001; Serreze et al. 2002). Moreover, understanding of the snowpack and snowmelt processes and their interactions with climatic change is limited, particularly for ungauged areas (Vörösmarty et al. 2001). Therefore, it is difficult to accurately simulate and predict the snowmelt process. Hydrological models are important tools in modeling hydrological processes and water resource management. Researchers have recently proposed some models to describe the snowmelt runoff process, such as the Soil and Water Assessment Tool (SWAT) (Gassman et al. 2007), Snowmelt Runoff Model (SRM) (Martinec 1975), and Snow Thermal Model (SNTHERM) (Jordan 1991). These models are generally driven by hydrometeorological information obtained from remote sensing satellites or ground observation stations, such as precipitation, snow cover, and temperature. However, the rigorous requirement for data collection limits the application of these models. Some land data assimilation models (LDAMs), such as Global Land Data Assimilation System (GLDAS) (Rodell et al. 2004), North American Land Data Assimilation System (NLDAS) (Mitchell et al. 2004), and Canadian Land Data Assimilation System (CaLDAS) (Carrera et al. 2015), can directly provide gridded snowmelt runoff information. The products of these models are effective and convenient for simulating snowmelt runoff processes with good performance (Bai et al. 2016; Campbell 2019; Wang et al. 2016).

As an overall modeling strategy, the GLDAS project drives multiple offline land surface models (LSMs) and incorporates data assimilation techniques, as well as satellite and groundbased observations, to determine the optimal states and fluxes of global surface water and energy, including snowmelt, surface, 
and subsurface runoff (Rodell et al. 2004). GLDAS provides an opportunity for assessing global and regional environmental changes, such as changes in the terrestrial water reserves (Chen et al. 2013; Singh et al. 2017), global spatiotemporal changes in drought (Chen et al. 2010; Ghazanfari et al. 2013), and changes in the soil water content (Bi et al. 2016; Chen et al. 2013). Currently, GLDAS drives four LSMs to generate datasets, including Noah (Chen et al. 1996; Ek et al. 2003), the Common Land Model (CLM) (Dai et al. 2003), Variable Infiltration Capacity (VIC) (Liang et al. 1994), and Mosaic (Koster and Suarez 1996). These LSMs use the meteorological forcing dataset to simulate land surface fluxes and states with a 15-min time step.

Zaitchik et al. (2010) used a source-to-sink routing method and global river discharge data to evaluate the performance of the four LSM datasets, and found that the evaluation results were greatly affected by the errors of the forcing data and paucity of observation data. Bai et al. (2016) assessed the four LSM datasets with baseflow separation results in the simulation of the total streamflow of the Tibetan Plateau, and their results demonstrated that the Noah model could better capture the seasonal and monthly variations in the total streamflow. Additionally, the Noah model data product of GLDAS fully covers our study area; thus, GLDAS Noah data were used to simulate the snowmelt runoff process in this study.

As the lateral runoff process and time lag related to storage in a river system are not considered in the GLDAS dataset, a routing model is required to convert the simulated runoff into surface streamflow at the basin outlet when using LSM-based runoff data. The linear reservoir and Muskingum routing methods are simple and computationally efficient ( $\mathrm{Li}$ et al. 2013), and are used to treat two routing parts in this study. Specifically, the linear reservoir routing method was used in the slope and river network convergence (Dai and Trenberth 2002; Li et al. 2013), and the Muskingum method was used in the river confluence section at the outlet of the study area (Yao et al. 2013; Zhao 1992).

Some parameters of the routing model should be calibrated before streamflow simulation, such as the areal mean free water capacity $(\mathrm{Sm})$ and the surface runoff regression coefficient (KS). The river routing model is typically applied based on a single set of parameters obtained via expert knowledge, literature, or an optimization procedure (Panday et al. 2014; J. L. Zhang et al. 2016; Zhang et al. 2007). However, it is difficult to accurately define or calibrate these parameters for highdimensional and complex hydrological models, particularly when limited observation data are available. Therefore, the routing results will inevitably be uncertain when using an optimized parameter set solely. To resolve this problem, we calibrated these parameters through Bayesian uncertainty analysis, that is, they were calibrated based on the probability distribution space, rather than a set of fixed values.

Markov chain Monte Carlo (MCMC) simulation is a popular Bayesian uncertainty analysis method that infers the posterior distributions of parameters by sampling from their prior distribution (Brooks 1998; Haario et al. 2004; J. Zhang et al. 2016, 2015). MCMC is conducted based on sampling algorithms, such as the Metropolis-Hastings ( $\mathrm{MH})$ or Differential Evolution Adaptive Metropolis (DREAMzs) algorithm. MCMC has been widely used for parameter uncertainty analysis in snowmelt runoff models. For example, Panday et al. (2014) used MH algorithm-based MCMC to calibrate the SRM parameters of the Tamor River basin in the eastern Nepalese Himalayas. Xie et al. (2019) used the DREAMzs algorithm-based MCMC to calibrate the SRM parameters in the Tizinafu River basin, and the results demonstrated that the DREAMzs can efficiently reduce and quantify model parameter uncertainty. In this study, the DREAMzs based MCMC was used to quantify the parameter uncertainty of the routing model. To our best knowledge, few studies have quantified the parameter uncertainty of river routing models in snowmelt water resource modeling, which is the first goal of this work.

The total streamflow simulated in this study consisted of surface streamflow and baseflow. However, it is impossible to directly measure each component of streamflow in practice. GLDAS only provides shallow groundwater runoff data, which do not consider groundwater runoff in confined (or deep) aquifers; therefore, the baseflow separation method must be used to evaluate the baseflow component (Aksoy et al. 2009). Currently, baseflow separation methods can be simply divided into tracer- and non-tracer-based methods. Although tracerbased methods have stronger physical mechanisms, the high cost of time and resources hinders their application (Mei and Anagnostou 2015). The commonly used non-tracer-based methods include the hydrograph separation program (HYSEP) (Sloto and Crouse 1996), baseflow index (BFI) (Bloomfield et al. 2009), digital filter (Chapman 1991; Nathan and Mcmahon 1990), and Kalinlin methods (Zeng et al. 2010). These methods are easy to use in baseflow separation. The graphical method is intuitive, but depends on empirical assumptions and the subjective judgment of the user. In this study, the four types of commonly used baseflow separation methods (such as the digital filter, BFI, HYSEP, and Kalinlin methods) were evaluated for modeling snowmelt runoff in the Tizinafu River basin, which is the second goal of this research.

The remainder of this paper is organized as follows. The study area is described in section 2 . In section 3 , the data and methods used are briefly described, including hydrometeorological data, the GLDAS dataset, routing method, and MCMC. The evaluation of snowmelt runoff modeling using the GLDAS dataset and different baseflow separation methods are discussed in section 4 . The conclusions drawn from the results and discussions are given in section 5 .

\section{Study area}

The Tizinafu River basin is the study area of this research, which is a typical arid and mountainous basin in the Kashi Region of Xinjiang Province, China (Fig. 1). This basin has an area of $5518 \mathrm{~km}^{2}$ with average annual precipitation of $120 \mathrm{~mm}$ from 2002 to 2010 and a mean temperature of $11.9^{\circ} \mathrm{C}$ at the basin outlet. As a typical arid and mountainous area, the Tizinafu River basin is characterized by low precipitation, high evaporation, and long snowfall periods. The streamflow of the Tizinafu River mainly originates from snowmelt water.

The Tizinafu River had an average streamflow of $24 \mathrm{~m}^{3} \mathrm{~s}^{-1}$ from 2002 to 2010, flows through the southeastern counties of Kashi, and finally joins the Yarkand River. Generally, the 


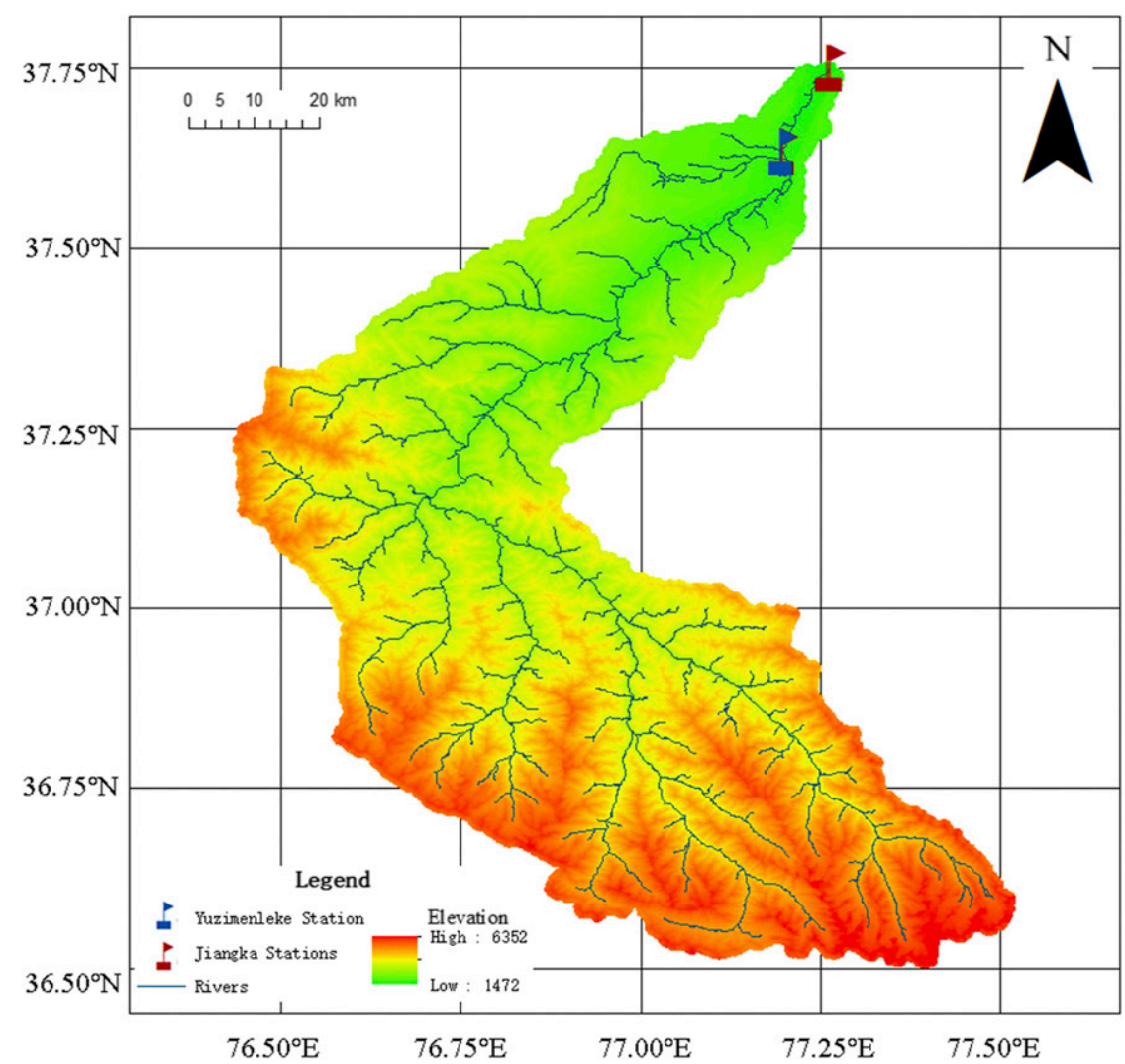

FIG. 1. Location and topography of the Tizinafu River basin.

snowmelt period of this basin is from May to September, and the snowpack period is from December to February.

\section{Data and methodology}

\section{a. Hydrometeorological data}

\section{1) STREAMFLOW}

The streamflow observation of the Tizinafu River basin represents the total streamflow, consisting of surface streamflow and baseflow. The daily streamflow data were collected from two hydrology stations, i.e., the Yuzimenleke (2002-07) and Jiangka (2008-10) Stations. Jiangka Station is located $16 \mathrm{~km}$ downstream of Yuzimenleke Station (Fig. 1). Yuzimenleke Station was shut down and then moved to Jiangka Station after 2007. In this study, we converted the streamflow at Jiangka Station to that at Yuzimenleke Station by multiplying the data by a relative coefficient, which was obtained by comparing the monthly average streamflow of a long time series between the two stations. The observed total streamflow data from 1 January 2002 to 31 December 2007 were used for model calibration, and the data from 1 January 2008 to 31 December 2010 were used for model verification. Figure 2 shows the curves of the observed total streamflow.

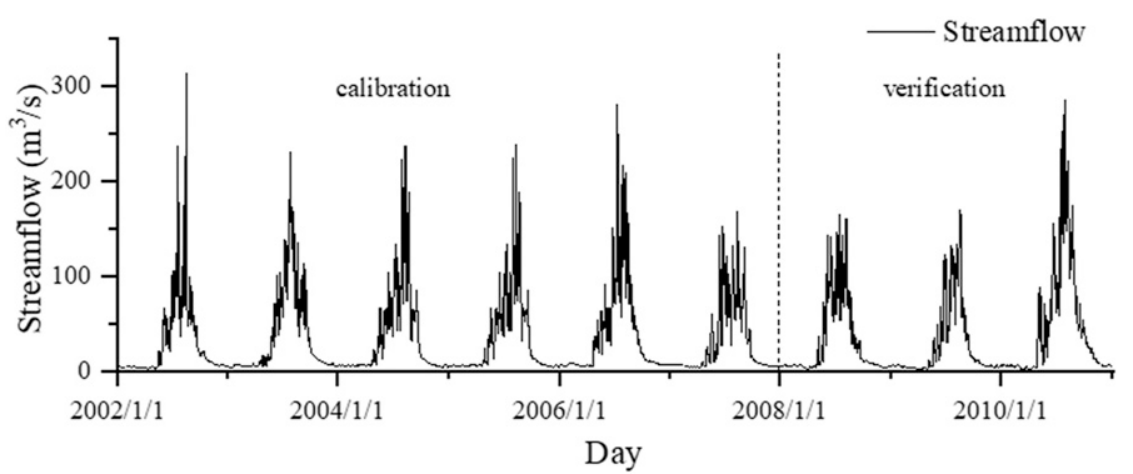

FIG. 2. Streamflow of the Tizinafu River basin from 2002 to 2010. 


\section{2) RUNOFF}

GLDAS Noah data were used to simulate the snowmelt process in this study. The Noah daily runoff product includes daily surface, subsurface, and snowmelt runoff data with a resolution of $0.25^{\circ}$ over the entire Tizinafu River basin. The surface and subsurface runoff were estimated based on the water balance equation (Schaake et al. 1996). The Noah runoff product from 1 January 2002 to 31 December 2010 was downloaded from the National Aeronautics and Space Administration (NASA) website at https://ldas.gsfc.nasa.gov/gldas.

\section{b. Routing model}

The total streamflow consists of the surface streamflow and baseflow. The surface streamflow was calculated using the routing model (RM). First, we added the GLDAS snowmelt runoff to the GLDAS surface runoff (without snowmelt) to obtain the total surface runoff (RS) in each grid cell. The RS was then stored using the free water storage reservoir model to obtain the slope runoff $(\mathrm{RL})$ in each grid cell. The slope runoff was routed using the linear reservoir routing method to calculate the river-network streamflow in each grid cell. Additionally, the surface streamflow from each grid cell was finally routed along the channels to the outlet of the Tizinafu River basin following the Muskingum method.

\section{1) SLOPE AND RIVER NETWORK RUNOFF}

The slope runoff in each grid cell is the part of the total surface runoff that exceeds the areal mean free water capacity of the surface soil layer $(\mathrm{Sm})$, which can be calculated using the following equations:

$$
\begin{aligned}
& \mathrm{RL}(t)=0, \text { when } \quad \mathrm{RS} \leq \mathrm{Sm} \\
& \mathrm{RL}(t)=\mathrm{RS}(t)-\mathrm{Sm}, \text { when } \mathrm{RS}>\mathrm{Sm},
\end{aligned}
$$

where RS is the total runoff, which is the sum of the surface (without snowmelt) and snowmelt runoff obtained from GLDAS; and Sm is the areal mean free water capacity of the surface soil layer.

According to the linear reservoir model, the slope runoff enters the river network and becomes the surface streamflow in each cell (SS), which can be calculated as

$$
\mathrm{SS}(t)=\mathrm{TSS}(t-1) \times \mathrm{KS}+\mathrm{RL}(t) \times(1-\mathrm{KS}) \times U,
$$

where $U$ is the unit conversion factor, $U=A /(3.6 \Delta t) ; A$ is the area of the grid cell; $\Delta t$ is the time interval; and $\mathrm{KS}$ is the surface runoff regression coefficient.

River network routing is the routing process of river flow entering the river channel from the slope within the grid cell. The dimensionless time unit line method was followed in this study, and the calculation equation is as follows:

$$
Q(t)=\sum_{i=1}^{n} \mathrm{UH}(i) \mathrm{TR}(t-i+1),
$$

where $Q(t)$ is the outflow of the cell at time $t, \mathrm{UH}$ is the dimensionless time unit line, and $n$ is the number of historical unit line periods.

\section{2) CHANNEL ROUTING}

The Muskingum routing method has been widely used in vector-based river channel routing due to its simplicity and lower computational cost than that of other methods (Gill 1978; Tung 1985), which calculates the surface streamflow at the outlet of the basin using the following equations:

$$
Q_{o}=C_{0} I_{2}+C_{1} I_{1}+C_{2} Q_{1},
$$

where $C_{0}, C_{1}$, and $C_{2}$ are routing coefficients given by

$$
\begin{aligned}
& C_{0}=\frac{0.5 \Delta t-K x}{0.5 \Delta t+K-K x}, \\
& C_{1}=\frac{0.5 \Delta t+K x}{0.5 \Delta t+K-K x}, \\
& C_{2}=\frac{-0.5 \Delta t+K x}{0.5 \Delta t+K-K x}, \\
& C_{0}+C_{1}+C_{2}=1,
\end{aligned}
$$

where $Q_{o}$ and $Q_{1}$ are the outflows of the upstream and downstream, respectively; $I_{1}$ and $I_{2}$ are the upstream and downstream inflow, respectively; $K$ and $x$ are the coefficients of the Muskingum method, where $K$ is the storage constant with the dimension of time and $x$ is a dimensionless constant reflecting the flood peak attenuation and shape during the movement of the diffuse wave; and $\Delta t$ is the routing time.

In this study, four important routing model parameters were considered as unknown random variables and will be calibrated through Bayesian model uncertainty, as defined in the uniform prior distributions shown in Table 2. The prior ranges of these parameters were set according to previous studies and the experience of experts (Wang et al. 2019; Strupczewski and Kundzewicz 1980; Guang-Te and Singh 1992). Based on the MCMC simulation, these unknown routing model parameters were identified by streamflow observations and then converged to posterior distributions, as shown in section $4 \mathrm{~b}$.

\section{c. Model evaluation metrics}

The Nash-Sutcliffe efficiency coefficient (NSE), relative error $(\mathrm{Re})$, and observation inclusion ratio $(C)$ by prediction intervals were used to evaluate the performance of the hydrological models:

$$
\begin{aligned}
\mathrm{NSE} & =1-\frac{\sum_{i=1}^{n}\left(Q_{o i}-Q_{s i}\right)^{2}}{\sum_{i=1}^{n}\left(Q_{o i}-\overline{Q_{o}}\right)^{2}}, \\
\mathrm{Re} & =\frac{\overline{Q_{o}}-\overline{Q_{s i}}}{\overline{Q_{o}}}, \\
C & =\frac{N_{c}}{N} .
\end{aligned}
$$

The NSE is defined in Eq. (9), where $Q_{o i}$ is the observation of the $i$ th day, $Q_{s i}$ is the simulated flow of the $i$ th day, and $\overline{Q_{o}}$ is the mean value of the observations. A larger NSE value indicates that the model output had better modeling performance. Re is 
defined in Eq. (10), where $\overline{Q_{o}}$ is the mean observed flow and $\overline{Q_{s i}}$ is the mean simulated flow. The performance of the model results is better when the Re value is closer to 0 . The metric of $C$ is defined in Eq. (11), where $N_{C}$ is the number of observations contained within the corresponding intervals of predictions, and $N$ is the number of observations. A higher $C$ value indicates that more observations are covered by the predictive intervals of the model outputs.

\section{d. Markov chain Monte Carlo simulation}

In Bayesian theory, the posterior probability of model parameters $\boldsymbol{\theta}, p(\boldsymbol{\theta} \mid \mathbf{d})$, is inferred through the Bayes formula

$$
p(\boldsymbol{\theta} \mid \mathbf{d})=\frac{L(\boldsymbol{\theta} \mid \mathbf{d}) p(\boldsymbol{\theta})}{\int L(\boldsymbol{\theta} \mid \mathbf{d}) p(\boldsymbol{\theta}) d \boldsymbol{\theta}}
$$

where $p(\boldsymbol{\theta})$ denotes the model parameters' prior distributions, and the likelihood function $L$ describes the structure of the residuals between the model output $\mathbf{f}$ and the observation $\mathbf{d}$. The independent and identically distributed Gaussian function is typically defined as the likelihood function, with the following formula:

$$
L(\boldsymbol{\theta} \mid \mathbf{d})=(2 \pi)^{-N / 2}|\mathbf{\Sigma}|^{-1 / 2} \exp \left[-\frac{1}{2}(\mathbf{d}-\mathbf{f})^{\mathrm{T}} \boldsymbol{\Sigma}^{-1}(\mathbf{d}-\mathbf{f})\right],
$$

where $N$ represents the number of data points and $\boldsymbol{\Sigma}$ is the covariance matrix.

It is generally difficult to infer the analytical expression of the posterior distribution $p(\boldsymbol{\theta} \mid \mathbf{d})$ directly through the Bayes formula, particularly for complex models with nonlinear and multivariate parameter spaces. The MCMC method provides an indirect and effective method of inferring $p(\boldsymbol{\theta} \mid \mathbf{d})$ by iteratively searching the parameters' posterior probability space. The posterior distribution $p(\boldsymbol{\theta} \mid \mathbf{d})$ is then produced based on the posterior parameter samples.

When performing MCMC to generate posterior parameter samples, the sampling algorithm of MCMC is used to generate candidate samples and store acceptable samples, which determines the efficiency and stability of MCMC. In this study, the commonly used sampling algorithm, DREAMzs (Laloy and Vrugt 2012), is used to equip MCMC. The DREAMzs has excellent performance in searching complex parameter space, such as the studies of Wöhling and Vrugt (2011), Zeng et al. (2016), and Fan et al. (2017). Readers interested in the DREAMzs algorithm can refer to Vrugt and Ter Braak (2011) and Laloy and Vrugt (2012).

\section{e. Baseflow separation methods}

The groundwater runoff data in GLDAS only represent shallow baseflow and cannot describe the entire baseflow, particularly in confined aquifers. Therefore, we used baseflow separation to represent the groundwater runoff component. In our study, 10 commonly used baseflow separation methods of four types were used to conduct baseflow modeling of the Tizinafu River basin, including four digital filter methods, two BFI methods, three HYSEP methods, and the Kalinlin method. Combined with the simulated surface streamflow, the
10 baseflow separation methods were evaluated by comparing their predictive performances for the total streamflow observations.

\section{1) Digital FILTERING METHODS}

Four digital filtering methods, i.e., the Lyne-Hollick (LH), Chapman improved (CI), Chapman-Maxwell (CM), and Boughton-Chapman (BC) methods, were used in this study. In the LH filter method (Lyne and Hollick 1979), the total streamflow $Q$ is divided into two parts: surface flow $Q_{q}$ and baseflow $Q_{b}$. The surface flow is calculated as

$$
Q_{q(t)}=\alpha Q_{q(t-1)}+\frac{1+\alpha}{2}\left[Q_{(t)}-Q_{(t-1)}\right]
$$

where $t$ is the time step (days), $\alpha$ is the filter parameter (recession constant; day ${ }^{-1}$ ), and $\alpha$ is 0.925 , according to Arnold et al. (2000). The baseflow $Q_{b}$ can then be given as

$$
Q_{b(t)}=Q_{(t)}-Q_{q(t)} .
$$

Chapman (1991) proposed an improved LH filter method (CI), which is calculated as

$$
Q_{q(t)}=\frac{3 k-1}{3-k} Q_{d(t-1)}+\frac{2}{3-k}\left[Q_{(t)}-Q_{(t-1)}\right]
$$

where $t$ is the time step (days); $k$ is the recession coefficient of the basin, which is usually $0.95 ; Q$ is the total streamflow; and $Q_{q}$ is the surface flow. The baseflow $Q_{b}$ can be calculated using Eq. (15).

In the CM filter method (Chapman and Maxwell 1996), the baseflow is calculated using the following equation:

$$
Q_{b(t)}=\frac{k}{2-k} Q_{b(t-1)}+\frac{1-k}{2-k} Q_{t}
$$

where $k$ is the recession coefficient of the basin, which is usually 0.95; $Q_{b(t-1)}$ is the filtered baseflow of the previous time of $t$; and $Q_{b(t)}$ is the filtered baseflow of time $t$.

The BC filter method was first developed by Boughton (1993), and Chapman and Maxwell (1996) introduced parameter $C$, which improved the flexibility of the algorithm. The separation equation then becomes

$$
Q_{b(t)}=\frac{k}{1+C} Q_{b(t-1)}+\frac{C}{1+C} Q_{(t)}
$$

where $k$ is the recession coefficient, with a value of 0.95 , and $C$ is a constant, with a value of 0.15 .

\section{2) BASEFLOW INDEX METHOD}

The BFI method was originally proposed by the U.K. Institute of Hydrology (Institute of Hydrology 1980), and the processing procedure can be summarized into the following steps (Mazvimavi et al. 2004):

(i) dividing the streamflow into blocks with a length of $1.6 \times$ $A^{0.2}$ days, where $A\left(\mathrm{~km}^{2}\right)$ is the area of the catchment;

(ii) denoting the minimum streamflow at each block as $B_{m}$ and then denoting $90 \%$ of $B_{m}$ as $B_{i}$;

(iii) defining $B_{m}$ as the baseflow $Q_{b i}$ when $B_{i}<B_{i-1}$ and $B_{i}<B_{i+1}$ 
(iv) linearly interpolating $Q_{\mathrm{bi}}$ to obtain the baseflow for each day.

In this study, we used two different BFI methods, i.e., the standard BFI (BFI-s) and improved BFI (BFI-i) methods. The difference between these two methods is the percentage of $B_{m}$, which was set to $90 \%$ and $97.915 \%$ for the standard and improved BFI methods, respectively (Wahl and Wahl 1995). More details regarding the BFI method can be found in Gustard et al. (1992), Mei and Anagnostou (2015), and Piggott et al. (2005).

\section{3) HYSEP METHOD}

The hydrograph separation program (HYSEP) method was first developed by Pettyjohn and Henning (1979), and contains three different algorithms, i.e., the fixed interval HYSEP (HYSEP-f), sliding interval HYSEP (HYSEP-s), and local minimum HYSEP (HYSEP-1) methods. The duration of surface runoff in the three HYSEP methods was computed using Eq. (19):

$$
N=(2.59 A)^{0.2}
$$

where $N$ is the number of days after which the surface runoff ceases and $A$ is the drainage area. The HYSEP-f method assumes the lowest discharge as the baseflow in each interval, and each interval is $2 N$ ( $N$ is the integer). The HYSEP-s method defines the lowest discharge in half of the interval minus one day $[0.5(2 N-1)$ days] as the baseflow (Chen and Teegavarapu 2020). The HYSEP-1 method uses the same interval as the HYSEP-s method, and assumes the baseflow by connecting the local minima of the hydrograph with straight lines (Eckhardt 2008). More detailed information about the three HYSEP methods will be found in Sloto and Crouse (1996).

\section{4) KALINLIN METHOD}

The Kalinlin method estimates the baseflow using the following equations:

$$
\begin{aligned}
& Q_{b(t)}=Q_{b(t-1)}[1-(1+\beta) \gamma]+\beta \gamma \bar{Q}_{i} \\
& Q_{b(t)}=Q_{b 0} e^{-\gamma i}
\end{aligned}
$$

where $Q_{b(t)}$ is the baseflow at time $t, Q_{b 0}$ is the initial baseflow, $\bar{Q}_{t}$ is the mean streamflow between time $t-1$ and $t, \gamma$ is the recession coefficient, and $\beta$ is a constant ratio of the recharge to surface flow. The recession coefficient $\gamma$ can be obtained by analyzing the recession curve for a certain period (at least 30 days in the dry season) using the least squares estimation method, according to Eq. (21). The ratio $\beta$ can be determined by the trial-and-error method. The values of $\gamma$ and $\beta$ were 0.018 and 0.325 in this study, respectively.

\section{Results and discussion}

In this section, the RMs combined with 10 different baseflow separation methods were calibrated through MCMC, and only the streamflow observations of the calibration period (from 1 January 2002 to 31 December 2007) were used. Subsequently, the calibrated RM and baseflow separation methods were verified through the streamflow records of the verification period (from 1 January 2008 to 31 December 2010). The RM with the 10 baseflow separation methods were denoted as RMLH (LH), RM-CI (CI), RM-CM (CM), RM-BC (BC), RM-Bs (BFI-s), RM-Bi (BFI-i), RM-Hf (HYSEP-f), RM-Hs (HYSEP-s), RM-Hl (HYSEP-1), and RM-K (Kalinlin). For example, RM-LH represents the surface streamflow produced by the RM and baseflow generated by the Lyne-Hollick method.

\section{a. Baseflow separation}

In this study, we adopted 10 baseflow separation methods of four types. Figure 3 shows the baseflow hydrographs of different separation methods. The proportion of baseflow in the total streamflow of each method is presented in Table 1, and the baseflow estimated by the 10 methods significantly differed. Figure 3 shows that the baseflow series of LH, CI, and CM were relatively stable, while that of the BC method fluctuated greatly during the flood season and was consistent with the streamflow hydrographs. The baseflow hydrographs of the BFI and HYSEP methods were almost lines connected by the lowest flow points, and BFI achieved relatively smoother baseflow hydrographs. Additionally, the improved BFI method continuously achieved a larger maximum value for the baseflow series than the standard BFI method each year. The baseflow hydrographs of the Kalinlin method generally took the same shape as the streamflow hydrographs, because this method uses a fixed ratio of baseflow to the total streamflow.

According to Table 1, the proportions of baseflow in the total streamflow estimated by different separation methods varied from $2.89 \%$ to $80.59 \%$. The annual average proportions of baseflow in the total streamflow estimated by the CI and CM methods were very small (about $3 \%$ ), while the proportions of baseflow calculated by the BFI and HYSEP methods were relatively high $(50 \%-80 \%)$. The baseflow proportion in each year obtained by the Kalinlin method was almost the same, which is because this method estimated the baseflow in a fixed proportion of the total streamflow. Additionally, the LH method achieved similar results for the proportions of baseflow with the Kalinin method.

\section{b. Posterior distributions of model parameters}

The prior distributions of the routing model parameters were assumed to obey uniform distributions, and their ranges are displayed in Table 2. The posterior distribution of the parameters obtained from the MCMC simulation is displayed in Fig. 4. The range of the horizontal axis represents the prior range of the corresponding parameter for each plot.

Figure 4 represents the posterior distributions of the RM parameters when using the 10 baseflow separation methods. The posterior parameter distributions of $K$ and $x$ inferred using different baseflow separation methods were not significantly different. However, the posterior distributions of KS and Sm differed between these methods. RM-LH, RM-BC, RM-Bs, RM-Bi, RM-Hs, and RM-K exhibited more concentrated posterior distributions than the other methods. The posterior distributions of parameters $K$ and $x$ indicated that these parameter samples were almost uniformly distributed in prior 


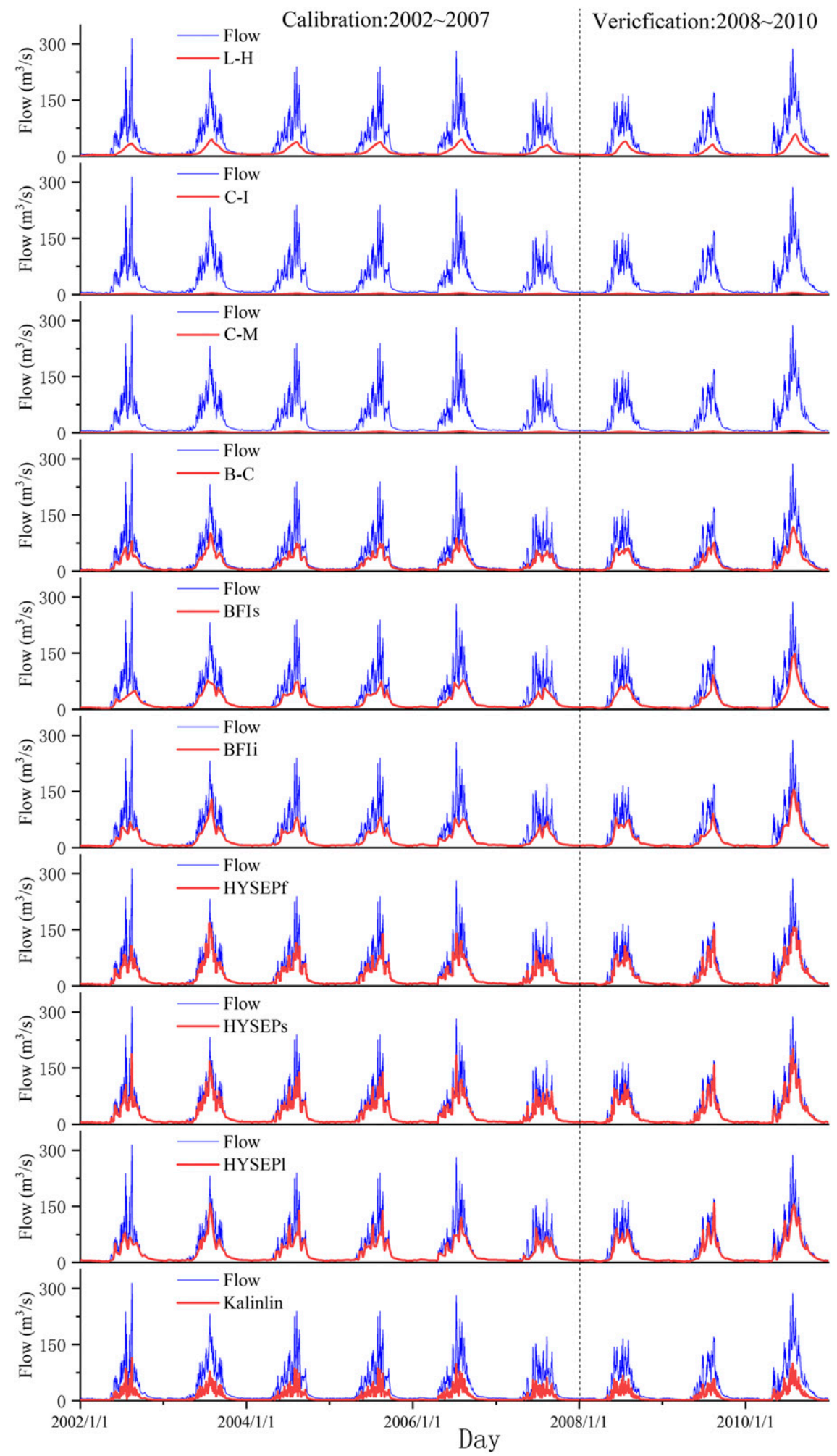

FIG. 3. The baseflow series obtained by the 10 separation methods, respectively. 
TABLE 1. The proportion of baseflow in total streamflow for different methods.

\begin{tabular}{|c|c|c|c|c|c|c|c|c|c|c|}
\hline & \multicolumn{4}{|c|}{ Digital filter methods } & \multicolumn{2}{|c|}{ BFI methods } & \multicolumn{3}{|c|}{ HYSEP methods } & \multirow[b]{2}{*}{ Kalinlin } \\
\hline & LH & $\mathrm{CI}$ & $\mathrm{CM}$ & $\mathrm{BC}$ & BFI-s & BFI-i & HYSEP-f & HYSEP-s & HYSEP-1 & \\
\hline 2002 & $30.61 \%$ & $2.89 \%$ & $3.00 \%$ & $51.59 \%$ & $50.52 \%$ & $60.95 \%$ & $71.51 \%$ & $71.57 \%$ & $66.86 \%$ & $33.33 \%$ \\
\hline 2003 & $33.73 \%$ & $3.04 \%$ & $3.05 \%$ & $56.14 \%$ & $62.69 \%$ & $68.64 \%$ & $80.59 \%$ & $78.27 \%$ & $75.61 \%$ & $33.33 \%$ \\
\hline 2004 & $34.01 \%$ & $2.98 \%$ & $3.00 \%$ & $52.77 \%$ & $58.26 \%$ & $60.81 \%$ & $73.36 \%$ & $74.24 \%$ & $71.88 \%$ & $33.33 \%$ \\
\hline 2005 & $33.88 \%$ & $2.98 \%$ & $2.99 \%$ & $52.74 \%$ & $56.78 \%$ & $59.93 \%$ & $72.87 \%$ & $74.21 \%$ & $71.84 \%$ & $33.33 \%$ \\
\hline 2006 & $33.62 \%$ & $3.09 \%$ & $3.10 \%$ & $53.67 \%$ & $59.28 \%$ & $62.12 \%$ & $73.54 \%$ & $74.27 \%$ & $68.44 \%$ & $33.34 \%$ \\
\hline 2007 & $33.87 \%$ & $3.00 \%$ & $3.01 \%$ & $51.83 \%$ & $56.15 \%$ & $59.42 \%$ & $74.45 \%$ & $73.23 \%$ & $66.71 \%$ & $33.33 \%$ \\
\hline 2008 & $33.61 \%$ & $3.05 \%$ & $3.06 \%$ & $55.69 \%$ & $62.07 \%$ & $68.86 \%$ & $75.54 \%$ & $76.69 \%$ & $72.63 \%$ & $33.33 \%$ \\
\hline 2009 & $28.90 \%$ & $3.04 \%$ & $3.05 \%$ & $53.71 \%$ & $58.90 \%$ & $59.38 \%$ & $77.28 \%$ & $76.50 \%$ & $75.88 \%$ & $33.33 \%$ \\
\hline 2010 & $30.14 \%$ & $3.04 \%$ & $3.04 \%$ & $56.32 \%$ & $61.44 \%$ & $69.14 \%$ & $78.37 \%$ & $79.23 \%$ & $75.39 \%$ & $33.33 \%$ \\
\hline Average & $32.49 \%$ & $3.01 \%$ & $3.03 \%$ & $53.83 \%$ & $58.45 \%$ & $63.25 \%$ & $75.28 \%$ & $75.36 \%$ & $71.69 \%$ & $33.33 \%$ \\
\hline
\end{tabular}

ranges; therefore, these parameters could not be effectively calibrated using the streamflow observations. In contrast, the posterior samples of parameter Sm and KS converged to the narrow ranges of the prior distributions. Therefore, $\mathrm{KS}$ and $\mathrm{Sm}$ were relatively more sensitive to the calibration data, which is validated by the result of sensitivity analysis (see Table S1 in the online supplemental material). This is because KS (surface runoff regression coefficient) and Sm (the areal mean free water capacity of the surface soil layer) determine the runoff concentration and separation, which significantly affect the total streamflow of the study area. In addition, the posterior distribution of $\mathrm{Sm}$ shows the characteristic of Gaussian distribution, while the posterior distribution of KS is not well defined.

\section{c. Model performance evaluation}

Figure 5 shows the streamflow simulations of the Tizinafu River basin during the calibration and verification periods using the routing model and 10 baseflow separation methods, respectively. The $95.0 \%(2.5 \%-97.5 \%)$ simulation interval at each observation was obtained from the frequency statistics of the corresponding posterior total streamflow simulation samples generated by MCMC simulation (15000 samples used in this study). The main streamflow characteristics could be captured by RM-BC, RM-Bs, RM-Bi, RM-Hf, RM-Hs, RM-Hl, and RM-K. However, RM-LH, RM-CI, and RM-CM failed to capture the streamflow characteristics; these models overall underestimated the streamflow records, which was mainly because the baseflow series of RM-LH, RM-CI, and RM-CM were underestimated and could not depict the baseflow process of the Tizinafu River basin. Among the RM with the 10 baseflow separation methods, RM-Hl outperformed the other nine methods in the total streamflow simulation. Additionally, all 10 methods failed to capture the peak of streamflow.

The observed and simulated total streamflow during the calibration and verification periods are compared in Fig. 6. The simulated streamflow is generated by using the parameter sample with the highest likelihood value for all 10 methods, and we found that the linear correlation coefficients $(R)$ between the observed and simulated total streamflow were relatively high $(R>0.74)$ for the BFI, HYSEP, and Kalinlin methods in both the calibration and verification periods. RM-Hl achieved the highest $R$ value (0.882 and 0.922$)$ during the calibration and verification periods. Meanwhile, the routing model with digital filter methods exhibited a relatively small $R$ value (ranging from 0.23 to 0.78 ) during the calibration and verification periods.

Table 3 lists the metrics used to evaluate the performances of the RM with the 10 baseflow separation methods during the calibration and verification periods. RM-Hl achieved the largest NSE coefficients and observation inclusion ratios $C$ among the 10 methods during both the calibration and verification periods, with NSE $=0.82$ and 0.93 , and $C=62.07 \%$ and $68.52 \%$, respectively. Additionally, among the 10 methods, $\mathrm{RM}-\mathrm{Hl}$ exhibited the smallest Re during the calibration period $(\mathrm{Re}=-0.40 \%)$ and the third-smallest during the verification period $(\mathrm{Re}=10.50 \%)$. Therefore, $\mathrm{RM}-\mathrm{Hl}$ achieved the best performance in modeling the streamflow of the Tizinafu River basin. Moreover, RM with digital filter methods exhibited weak performance in total streamflow modeling, particularly for RM-LH, RM-CI, and RM-CM, as these models had very small NSE and $C$ values, and larger Re values.

The relatively high proportion of baseflow in the total streamflow estimated by the HYSEP-1 method $(71.69 \%$ on average) does not indicate that groundwater contributes most of the water resources of the Tizinafu River basin. The study area of our research is a typical cold and arid mountainous basin in which the interactions between river flow and groundwater are relatively strong. During the snowpack period, the streamflow of the Tizinafu River basin is mainly contributed by baseflow. However, during the snowmelt period, the snowmelt runoff recharges the groundwater in the upper reaches, and the groundwater then discharges to the river flow in the lower reaches. Therefore, the baseflow constitutes a relatively high proportion of the total streamflow, and the HYSEP baseflow separation methods performed well in the total streamflow simulation.

The interactions between groundwater and surface water are influenced by many factors, such as the climate and

TABLE 2. Parameters' prior distribution ranges.

\begin{tabular}{lcccc}
\hline Parameters & $K$ & $x$ & KS & Sm $(\mathrm{mm})$ \\
\hline Minimal value & 16 & 0.0 & 0.95 & 10 \\
Maximal value & 24 & 0.6 & 1.00 & 50 \\
\hline
\end{tabular}



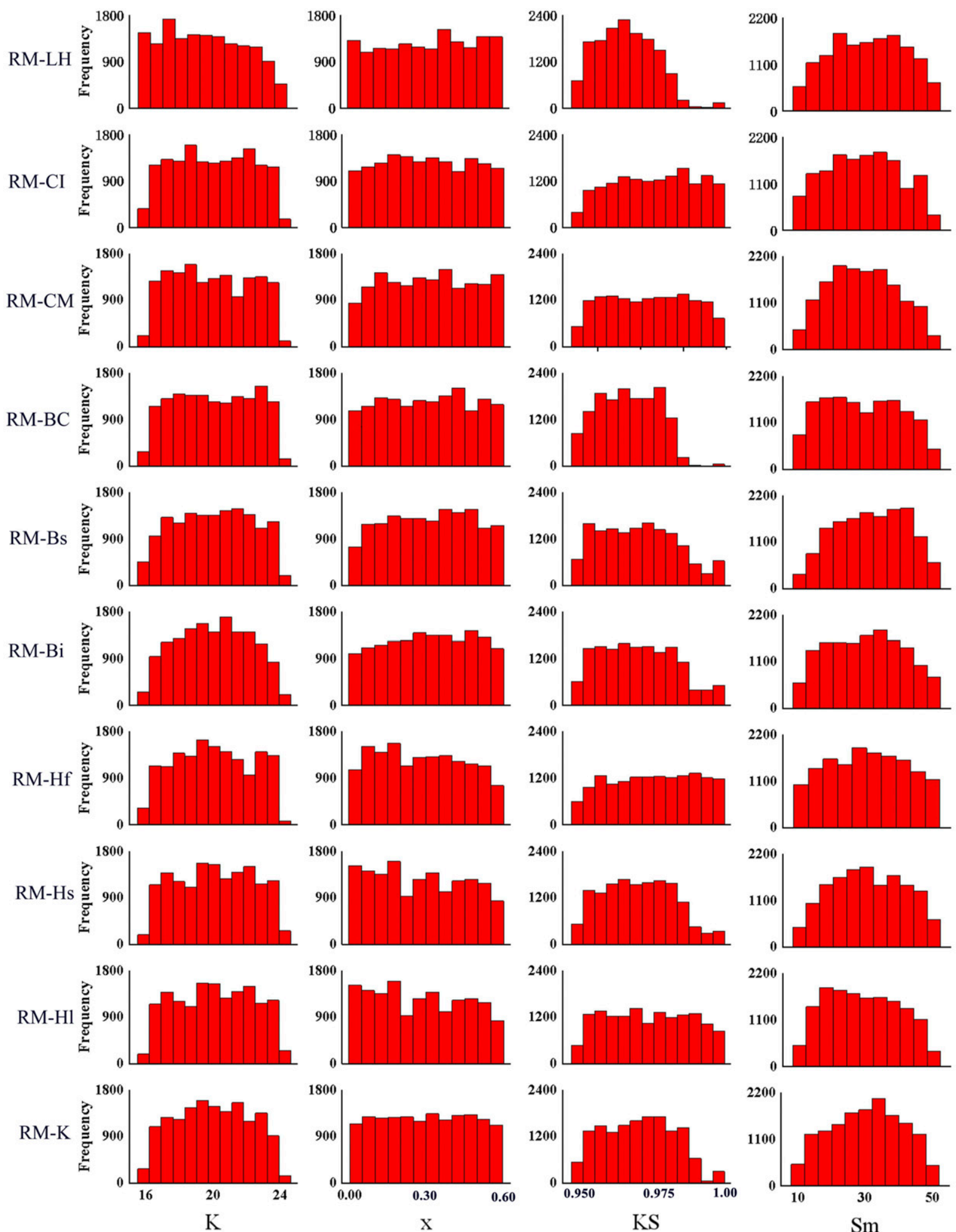

FIG. 4. The posterior distributions of routing model parameters with the 10 baseflow separation methods, respectively. 


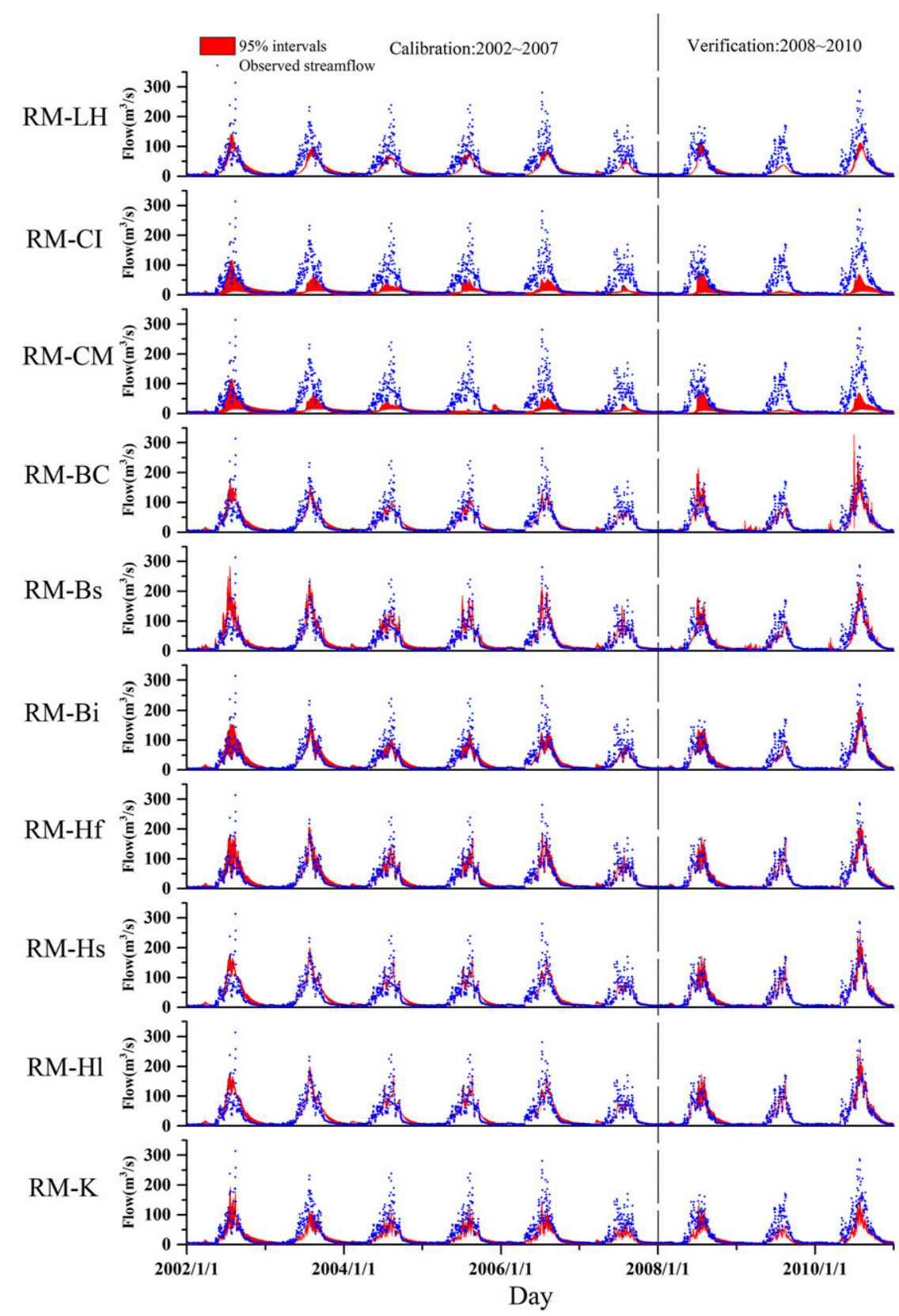

FIG. 5. The $95 \%$ predictive interval of streamflow in calibration and verification periods for the 10 baseflow separation methods, respectively.

topographic conditions, and anthropogenic activities, which vary in temporal and spatial scales, especially in arid and mountainous areas such as the Tizinafu River basin. In recent decades, a number of integrated groundwater-surface water models have been developed to quantify the interactions between groundwater and surface water, such as MIKE SHE (Graham and Butts 2005), GSFLOW (Markstrom et al. 2008), and HydroGeoSphere (Therrien et al. 2010). These models incorporate groundwater and surface water modules and obtain good performance in simulating the entire hydrological process (Harbaugh 2005). Additionally, geochemical methods can also be used to quantify the interactions between groundwater and surface water, such as the isotope tracing method (Arnoux et al. 2017). However, this is beyond the scope of our research, and we will focus on these issues in our subsequent work.

\section{Summary and conclusions}

In this study, the GLDAS runoff data-driven RM was applied to simulate the snowmelt runoff process in the Tizinafu River basin, an arid and high-altitude mountainous area of northwest China. To calibrate the parameter uncertainty of the 

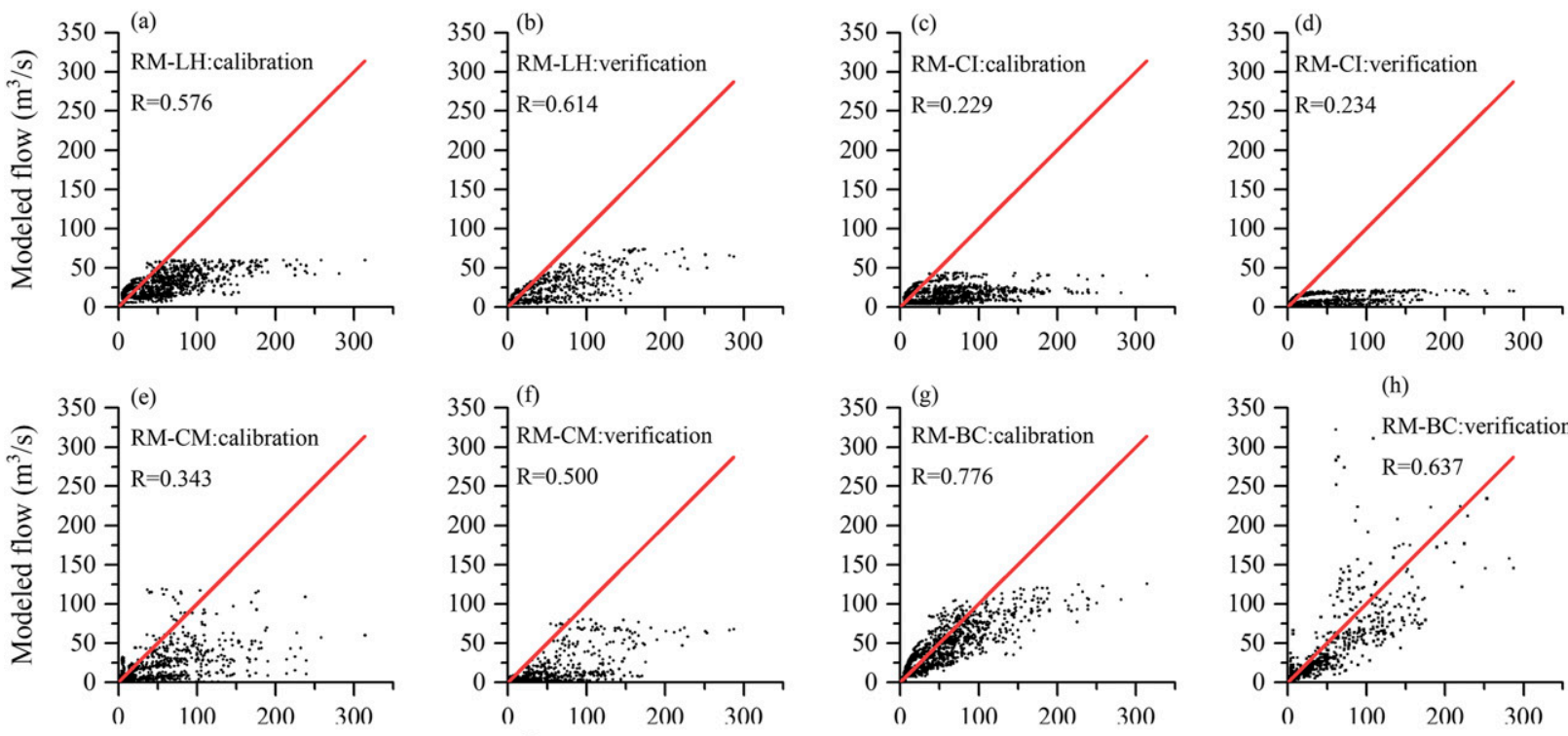

(h)
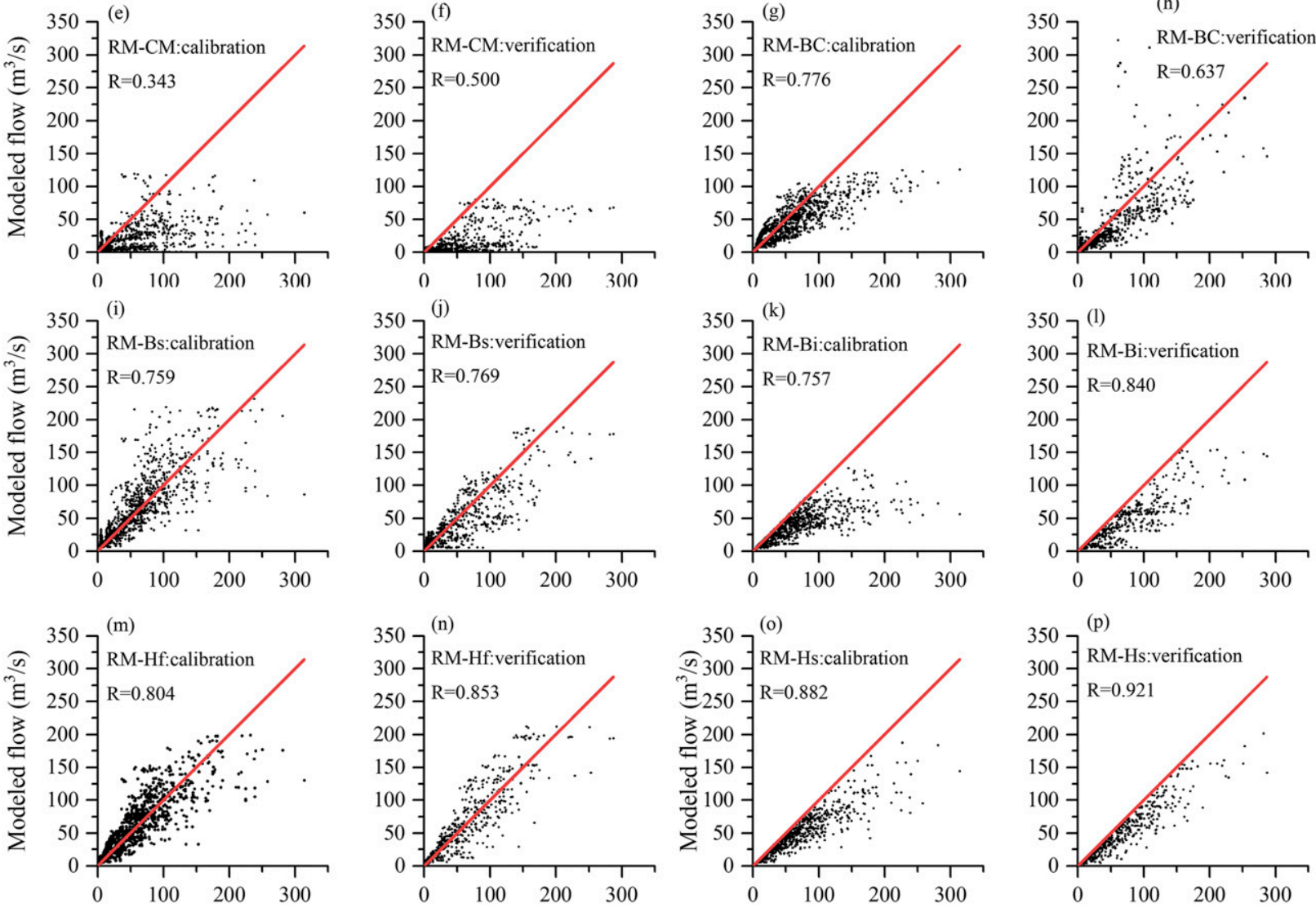

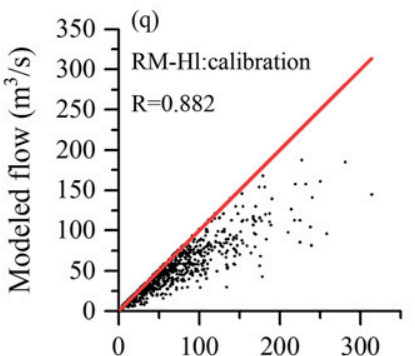

Observed flow $\left(\mathrm{m}^{3} / \mathrm{s}\right)$

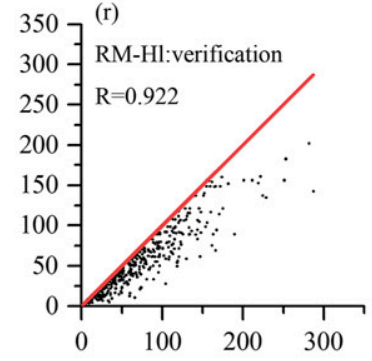

Observed flow $\left(\mathrm{m}^{3} / \mathrm{s}\right)$

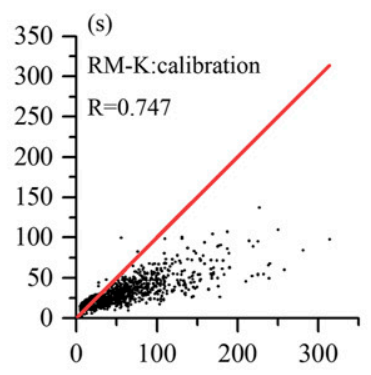

Observed flow $\left(\mathrm{m}^{3} / \mathrm{s}\right)$
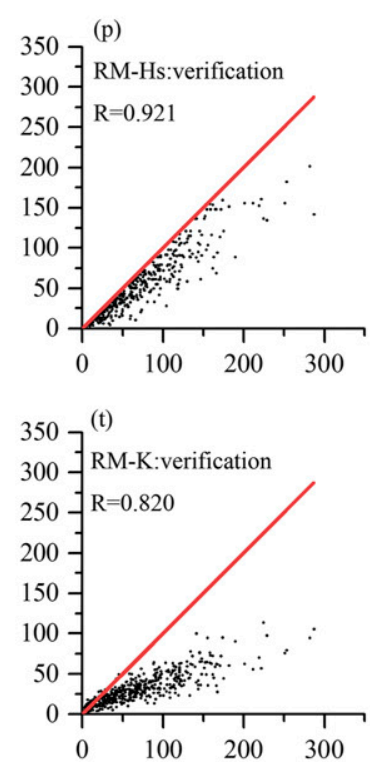

Observed flow $\left(\mathrm{m}^{3} / \mathrm{s}\right)$

FIG. 6. The comparisons between the observed and modeled streamflow for the 10 baseflow separation methods. The modeled streamflow is obtained by using the parameter sample with the highest likelihood value. 
TABLE 3. The Nash-Sutcliffe efficiency coefficient (NSE), the observation inclusion ratio $(C)$ and relative error (Re) of the 10 methods.

\begin{tabular}{|c|c|c|c|c|c|c|}
\hline & \multicolumn{2}{|c|}{ NSE } & \multicolumn{2}{|c|}{$\mathrm{Re}$} & \multicolumn{2}{|c|}{$C(\%)$} \\
\hline & Calibration & Verification & Calibration & Verification & Calibration & Verification \\
\hline RM-LH & 0.26 & 0.34 & $-42.60 \%$ & $-45.40 \%$ & $34.09 \%$ & $26.71 \%$ \\
\hline RM-CI & -0.48 & -0.46 & $-92.70 \%$ & $-92.60 \%$ & $38.68 \%$ & $26.71 \%$ \\
\hline RM-CM & 0.03 & 0.01 & $-71.30 \%$ & $-73.70 \%$ & $48.52 \%$ & $36.21 \%$ \\
\hline RM-BC & 0.64 & 0.79 & $-22.30 \%$ & $-19.40 \%$ & $35.33 \%$ & $37.86 \%$ \\
\hline RM-Bs & 0.58 & 0.56 & $-10.20 \%$ & $-21.00 \%$ & $39.84 \%$ & $41.53 \%$ \\
\hline RM-Bi & 0.62 & 0.88 & $-13.60 \%$ & $5.90 \%$ & $39.16 \%$ & $31.05 \%$ \\
\hline RM-Hf & 0.71 & 0.46 & $-10.60 \%$ & $-32.90 \%$ & $22.04 \%$ & $19.01 \%$ \\
\hline RM-Hs & 0.78 & 0.92 & $6.90 \%$ & $10.20 \%$ & $41.94 \%$ & $41.96 \%$ \\
\hline RM-Hl & 0.82 & 0.93 & $-0.40 \%$ & $10.50 \%$ & $62.07 \%$ & $68.52 \%$ \\
\hline RM-K & 0.40 & 0.44 & $-43.10 \%$ & $-45.30 \%$ & $33.44 \%$ & $47.60 \%$ \\
\hline
\end{tabular}

RM, we coupled it with MCMC simulation. Additionally, we evaluated 10 commonly used baseflow separation methods to describe the baseflow of the study area. This research has reference value for applying GLDAS runoff data in modeling the snowmelt runoff processes and the baseflow of the arid, cold, and high-altitude mountainous areas with limited field observations. Several key findings can be summarized based on the results and discussion, as follows:

1) Based on the MCMC simulation-based parameter uncertainty quantification, the routing model with GLDAS runoff data could reproduce the snowmelt runoff process of the Tizinafu River basin. The RM-Hl achieved NSE coefficients of 0.82 and 0.93 , Re of $0.40 \%$ and $10.50 \%$, and observation inclusion ratios of $62.07 \%$ and $68.52 \%$, for the calibration and verification periods, respectively. However, the RM with the 10 baseflow separation methods failed to capture the total streamflow peak during the flood season.

2) The HYSEP-1 method was the most suitable of the 10 commonly used baseflow separation methods for describing the baseflow of the Tizinafu River basin. The routing model with the HYSEP-1 method achieved the best performance in modeling the total streamflow records of the study area among the 10 methods during both the calibration and verification periods.

3) The generation of baseflow series greatly differed between the 10 baseflow separation methods. The digital filter methods exhibited weak performance in baseflow separation for the Tizinafu River basin, particularly for the $\mathrm{LH}$, CI, and CM methods.

Acknowledgments. This study was supported by the National Natural Science Foundation of China (41730856, 42072272, U1603343), and the Fundamental Research Funds for the Central Universities (0206-14380106). The daily streamflow data was provided by the Xinjiang Tarim River Basin Authority, China: http://www.tahe.gov.cn/. The GLDAS data were downloaded from https://ldas.gsfc.nasa.gov/gldas.

\section{REFERENCES}

Aksoy, H., I. Kurt, and E. Eris, 2009: Filtered smoothed minima baseflow separation method. J. Hydrol., 372, 94-101, https:// doi.org/10.1016/j.jhydrol.2009.03.037.
Arnold, J. G., R. S. Muttiah, R. Srinivasan, and P. M. Allen, 2000: Regional estimation of base flow and groundwater recharge in the Upper Mississippi river basin. J. Hydrol., 227, 21-40, https://doi.org/10.1016/S0022-1694(99)00139-0.

Arnoux, M., F. Barbecot, E. Gibert-Brunet, J. Gibson, E. Rosa, A. Noret, and G. Monvoisin, 2017: Geochemical and isotopic mass balances of kettle lakes in southern Quebec (Canada) as tools to document variations in groundwater quantity and quality. Environ. Earth Sci., 76, 106, https://doi.org/10.1007/ s12665-017-6410-6.

Bai, P., X. Liu, T. Yang, K. Liang, and C. Liu, 2016: Evaluation of streamflow simulation results of land surface models in GLDAS on the Tibetan Plateau. J. Geophys. Res. Atmos., 121, 12 180-12 197, https://doi.org/10.1002/2016JD025501.

Bi, H., J. Ma, W. Zheng, and J. Zeng, 2016: Comparison of soil moisture in GLDAS model simulations and in situ observations over the Tibetan Plateau. J. Geophys. Res. Atmos., 121, 2658-2678, https://doi.org/10.1002/2015JD024131.

Bloomfield, J. P., D. J. Allen, and K. J. Griffiths, 2009: Examining geological controls on baseflow index (BFI) using regression analysis: An illustration from the Thames Basin, UK. J. Hydrol., 373, 164-176, https://doi.org/10.1016/ j.jhydrol.2009.04.025.

Boughton, W. C., 1993: A hydrograph-based model for estimating the water yield of ungauged catchments. Natl. Conf. Publ. Inst. Eng., Aust., 93, 317-324.

Brooks, S. P., 1998: Markov chain Monte Carlo method and its application. Statistician, 47, 69-100, https://doi.org/10.1111/ 1467-9884.00117.

Campbell, D. R., 2019: Early snowmelt projected to cause population decline in a subalpine plant. Proc. Natl. Acad. Sci. USA, 116, 12 901-12 906, https://doi.org/10.1073/pnas. 1820096116.

Carrera, M. L., S. Belair, and B. Bilodeau, 2015: The Canadian Land Data Assimilation System (CaLDAS): Description and synthetic evaluation study. J. Hydrometeor., 16, 1293-1314, https://doi.org/10.1175/JHM-D-14-0089.1.

Chapman, T. G., 1991: Comment on "Evaluation of automated techniques for base flow and recession analyses" by R. J. Nathan and T. A. McMahon. Water Resour. Res., 27, 1783-1784, https://doi.org/10.1029/91WR01007.

_ numerical methods with tracer experiments. Natl. Conf. Publ. Inst. Eng., Aust., 96/05, 539-545.

Chen, F., and Coauthors, 1996: Modeling of land surface evaporation by four schemes and comparison with FIFE 
observations. J. Geophys. Res., 101, 7251-7268, https:// doi.org/10.1029/95JD02165.

Chen, H., and R. S. V. Teegavarapu, 2020: Comparative analysis of four baseflow separation methods in the south Atlantic-Gulf Region of the U.S. Water, 12, 120, https://doi.org/10.3390/ w12010120.

Chen, J., and Coauthors, 2010: Recent La Plata basin drought conditions observed by satellite gravimetry. J. Geophys. Res., 115, D22108, https://doi.org/10.1029/2010JD014689.

Chen, Y., K. Yang, J. Qin, L. Zhao, W. Tang, and M. Han, 2013: Evaluation of AMSR-E retrievals and GLDAS simulations against observations of a soil moisture network on the central Tibetan Plateau. J. Geophys. Res. Atmos., 118, 4466-4475, https://doi.org/10.1002/jgrd.50301.

Dai, A., and K. E. Trenberth, 2002: Estimates of freshwater discharge from continents: Latitudinal and seasonal variations. J. Hydrometeor., 3, 660-687, https://doi.org/10.1175/15257541(2002)003<0660:EOFDFC $>2.0 . C O ; 2$.

Dai, Y., and Coauthors, 2003: The Common Land Model. Bull. Amer. Meteor. Soc., 84, 1013-1024, https://doi.org/10.1175/ BAMS-84-8-1013.

Eckhardt, K., 2008: A comparison of baseflow indices, which were calculated with seven different baseflow separation methods. J. Hydrol., 352, 168-173, https://doi.org/10.1016/ j.jhydrol.2008.01.005.

Ek, M. B., K. E. Mitchell, Y. Lin, E. Rogers, P. Grunmann, V. Koren, G. Gayno, and J. D. Tarpley, 2003: Implementation of Noah land surface model advances in the National Centers for Environmental Prediction operational mesoscale Eta model. J. Geophys. Res., 108, 8851, https://doi.org/10.1029/ 2002JD003296.

Fan, Y., G. Huang, B. W. Baetz, Y. Li, and K. Huang, 2017: Development of a Copula-based Particle Filter (CopPF) approach for hydrologic data assimilation under consideration of parameter interdependence. Water Resour. Res., 53, 48504875, https://doi.org/10.1002/2016WR020144.

Gassman, P. W., M. R. Reyes, C. H. Green, and J. G. Arnold, 2007: The soil and water assessment tool: Historical development, applications, and future research directions. Trans. ASABE, 50, 1211-1250, https://doi.org/10.13031/2013.23637.

Ghazanfari, S., S. Pande, M. Hashemy, and B. Sonneveld, 2013: Diagnosis of GLDAS LSM based aridity index and dryland identification. J. Environ. Manage., 119, 162-172, https:// doi.org/10.1016/j.jenvman.2013.01.040.

Gill, M. A., 1978: Flood routing by the Muskingum method. J. Hydrol., 36, 353-363, https://doi.org/10.1016/0022-1694(78) 90153-1.

Graham, D. N., and M. B. Butts, 2005: Flexible, integrated watershed modelling with MIKE SHE. Watershed Models. V. P. Singh and D. K. Frevert, Eds., CRC Press, 245-272.

Guang-Te, W., and V. P. Singh, 1992: Muskingum method with variable parameters for flood routing in channels. J. Hydrol., 134, 57-76, https://doi.org/10.1016/0022-1694(92)90028-T.

Gustard, A., A. Bullock, and J. M. Dixon, 1992: Low flow estimation in the United Kingdom. Institute of Hydrology Rep. 108, 88 pp., http://nora.nerc.ac.uk/id/eprint/6050/1/IH_108.pdf.

Haario, H., M. Laine, M. Lehtinen, E. Saksman, and J. Tamminen, 2004: Markov chain Monte Carlo methods for high dimensional inversion in remote sensing. J. Roy. Stat. Soc., 66B, 591607, https://doi.org/10.1111/j.1467-9868.2004.02053.x.

Harbaugh, A. W., 2005: MODFLOW-2005, the U.S. Geological Survey's modular ground water flow model. USGS Techniques and Methods, 6-A16, 253 pp., https://doi.org/10.3133/tm6A16.
Institute of Hydrology, 1980: Low flow studies. Institute of Hydrology, 42 pp., http://nora.nerc.ac.uk/id/eprint/9093/1/ Low_Flow_01.pdf.

Jordan, R., 1991: A one-dimensional temperature model for a snow cover: Technical documentation for SNTERERM.89. Special Rep. 91-16, Cold Region Research and Engineers Laboratory, U.S. Army Corps of Engineers, Hanover, NH, 61 pp.

Koster, R. D., and M. J. Suarez, 1996: Energy and water balance calculations in the Mosaic LSM. NASA Tech. Memo. 104606, Vol. 9 , 60 pp., http://gmao.gsfc.nasa.gov/pubs/docs/Koster130.pdf.

Laloy, E., and J. A. Vrugt, 2012: High-dimensional posterior exploration of hydrologic models using multiple-try $\operatorname{DREAM}_{(\mathrm{ZS})}$ and high-performance computing. Water Resour. Res., 48, 182205, https://doi.org/10.1029/2011WR010608.

Lammers, R. B., A. I. Shiklomanov, C. J. Vörösmarty, B. M. Fekete, and B. J. Peterson, 2001: Assessment of contemporary Arctic river runoff based on observational discharge records. J. Geophys. Res., 106, 3321-3334, https://doi.org/10.1029/ 2000JD900444.

Li, H., M. S. Wigmosta, H. Wu, M. Huang, Y. Ke, A. M. Coleman, and L. R. Leung, 2013: A physically based runoff routing model for land surface and earth system models. J. Hydrometeor., 14, 808-828, https://doi.org/10.1175/JHM-D-12-015.1.

Liang, X., D. P. Lettenmaier, E. F. Wood, and S. J. Burges, 1994: A simple hydrologically based model of land-surface water and energy fluxes for general-circulation models. J. Geophys. Res., 99, 14 415-14 428, https://doi.org/10.1029/94JD00483.

Liston, G. E., and K. Elder, 2006: A distributed snow-evolution modeling system (SnowModel). J. Hydrometeor., 7, 12591276, https://doi.org/10.1175/JHM548.1.

Lyne, V. D., and M. Hollick, 1979: Stochastic time-variable rainfall-runoff modeling. Natl. Conf. Publ. - Inst. Eng., Aust., 79/10, 89-93.

Markstrom, S. L., R. G. Niswonger, R. S. Regan, D. E. Prudic, and P. M. Barlow, 2008: GSFLOW-Coupled ground-water and surface-water FLOW model based on the integration of the Precipitation-Runoff Modeling System (PRMS) and the Modular Ground-Water Flow Model (MODFLOW-2005). USGS Techniques and Methods 6-D1, 240 pp., https:// pubs.usgs.gov/tm/tm6d1/.

Marsh, P., 1999: Snowcover formation and melt: Recent advances and future prospects. Hydrol. Processes, 13, 2117-2134, https:// doi.org/10.1002/(SICI)1099-1085(199910)13:14/15<2117::AIDHYP869>3.0.CO;2-9.

Martinec, J., 1975: Snowmelt runoff model for stream flow forecasts. Hydrol. Res., 6, 145-154, https://doi.org/10.2166/ nh.1975.0010.

Mazvimavi, D., A. M. J. Meijerink, and A. Stein, 2004: Prediction of base flows from basin characteristics: A case study from Zimbabwe. Hydrol. Sci. J., 49, 703-715, https://doi.org/10.1623/ hysj.49.4.703.54428.

Mei, Y., and E. N. Anagnostou, 2015: A hydrograph separation method based on information from rainfall and runoff records. J. Hydrol., 523, 636-649, https://doi.org/10.1016/j.jhydrol.2015. 01.083.

Mitchell, K. E., and Coauthors, 2004: The multi-institution North American Land Data Assimilation System (NLDAS): Utilizing multiple GCIP products and partners in a continental distributed hydrological modeling system. J. Geophys. Res., 109, D07S90, https://doi.org/10.1029/2003JD003823.

Nathan, R. J., and T. A. Mcmahon, 1990: Evaluation of automated techniques for base-flow and recession analyses. Water Resour. Res., 26, 1465-1473, https://doi.org/10.1029/WR026i007p01465. 
Panday, P. K., C. A. Williams, K. E. Frey, and M. E. Brown, 2014: Application and evaluation of a snowmelt runoff model in the Tamor River basin, Eastern Himalaya using a Markov Chain Monte Carlo (MCMC) data assimilation approach. Hydrol. Processes, 28, 5337-5353, https://doi.org/10.1002/hyp.10005.

Pettyjohn, W. A., and R. J. Henning, 1979: Preliminary estimate of regional effective ground-water recharge rates in Ohio. Project Completion Rep. 552, Water Resources Center, Ohio State University, 323 pp., https://kb.osu.edu/handle/1811/36354.

Piggott, A. R., S. Moin, and C. Southam, 2005: A revised approach to the UKIH method for the calculation of baseflow. Hydrol. Sci. J., 50, 911-920, https://doi.org/10.1623/hysj.2005.50.5.911.

Rodell, M., and Coauthors, 2004: The Global Land Data Assimilation System. Bull. Amer. Meteor. Soc., 85, 381-394, https://doi.org/10.1175/BAMS-85-3-381.

Schaake, J. C., V. I. Koren, Q. Y. Duan, K. Mitchell, and F. Chen, 1996: Simple water balance model for estimating runoff at different spatial and temporal scales. J. Geophys. Res., 101, 7461-7475, https://doi.org/10.1029/95JD02892.

Serreze, M. C., D. H. Bromwich, M. P. Clark, A. J. Etringer, T. Zhang, and R. Lammers, 2002: Large-scale hydro-climatology of the terrestrial Arctic drainage system. J. Geophys. Res., 108, 8160, https://doi.org/10.1029/2001JD000919.

Singh, A. K., and Coauthors, 2017: Estimation of quantitative measures of total water storage variation from GRACE and GLDAS-NOAH satellites using geospatial technology. Quat. Int., 444, 191-200, https://doi.org/10.1016/j.quaint.2017.04.014.

Sloto, R. A., and M. Y. Crouse, 1996: HYSEP: A computer program for streamflow hydrograph separation and analysis. U.S. Geological Survey Water-Resources Investigations Rep. 96-4040, 54 pp., https://doi.org/10.3133/wri964040.

Strupczewski, W. G., and Z. W. Kundzewicz, 1980: Muskingum method revisited. J. Hydrol., 48, 327-342, https://doi.org/ 10.1016/0022-1694(80)90124-9.

Therrien, R., R. McLaren, E. Sudicky, and S. Panday, 2010: HydroGeoSphere: A three-dimensional numerical model describing fully-integrated subsurface and surface flow and solute transport. University of Waterloo and Université Laval, 456 pp., https://www.ggl.ulaval.ca/fileadmin/ggl/documents/ rtherrien/hydrogeosphere.pdf.

Tung, Y. K., 1985: River flood routing by nonlinear Muskingum method. J. Hydraul. Eng., 111, 1447-1460, https://doi.org/ 10.1061/(ASCE)0733-9429(1985)111:12(1447).

Vörösmarty, C., and Coauthors, 2001: The hydrologic cycle and its role in Arctic and global environmental change: A rationale and strategy for synthesis study, Arctic Research Consortium of the U.S., 84 pp.

Vrugt, J. A., and C. J. F. Ter Braak, 2011: DREAM(D): An adaptive Markov chain Monte Carlo simulation algorithm to solve discrete, noncontinuous, and combinatorial posterior parameter estimation problems. Hydrol. Earth Syst. Sci., 15, 37013713, https://doi.org/10.5194/hess-15-3701-2011.

Wahl, K. L., and T. L. Wahl, 1995: Determining the flow of Comal Springs at New Braunfels, Texas. Texas Water '95, San Antonio, TX, American Society of Civil Engineers, 77-86, http://www.usbr.gov/tsc/techreferences/hydraulics_lab/pubs/ PAP/PAP-0708.pdf.
Wang, Q., Y. Liu, X. Zhang, and B. Yaquan, 2019: Improvement research of flood routing model in Aksu River basin. IOP Conf. Ser.: Earth Environ., 300, 032011, https://doi.org/ 10.1088/1755-1315/330/3/032011.

Wang, W., W. Cui, X. Wang, and X. Chen, 2016: Evaluation of GLDAS-1 and GLDAS-2 forcing data and Noah model simulations over China at the monthly scale. J. Hydrometeor., 17, 2815-2833, https://doi.org/10.1175/JHM-D-15-0191.1.

Wöhling, T., and J. A. Vrugt, 2011: Multiresponse multilayer vadose zone model calibration using Markov chain Monte Carlo simulation and field water retention data. Water Resour. Res., 47, W04510, https://doi.org/10.1029/2010WR009265.

Xie, W., X. Zeng, S. Zhang, J. Wu, D. Wang, and X. Zhu, 2019: Bayesian evaluation of meteorological datasets for modeling snowmelt runoff in Tizinafu watershed in Western China. Theor. Appl. Climatol., 138, 1991-2006, https://doi.org/ 10.1007/s00704-019-02944-3.

Yang, D., D. Robinson, Y. Zhao, T. Estilow, and B. Ye, 2003: Streamflow response to seasonal snow cover extent changes in large Siberian watersheds. J. Geophys. Res., 108, 4578, https:// doi.org/10.1029/2002JD003149.

Yao, C., Y. Zhang, and Z. Li, 2013: Application and comparison of cell-to-cell diffusion wave and Muskingum routing methods. J. Hohai Univ., 41, 6-10, https://doi.org/10.3876/j.issn.10001980.2013.01.002.

Zaitchik, B. F., M. Rodell, and F. Olivera, 2010: Evaluation of the Global Land Data Assimilation System using global river discharge data and a source-to-sink routing scheme. Water Resour. Res., 46, W06507, https://doi.org/10.1029/2009WR007811.

Zeng, S., J. Chen, and F. Sheng, 2010: Application of environment isotope in base flow calculation for small costal basin in Zhuhai. J. China Hydrol., 2010-02, https://en.cnki.com.cn/ Article_en/CJFDTotal-SWZZ201002006.htm.

Zeng, X., J. Wu, D. Wang, and X. Zhu, 2016: Assessing the pollution risk of a groundwater source field at western Laizhou Bay under seawater intrusion. Environ. Res., 148, 586-594, https://doi.org/10.1016/j.envres.2015.11.022.

Zhang, J., L. Zeng, C. Chen, D. Chen, and L. Wu, 2015: Efficient Bayesian experimental design for contaminant source identification. Water Resour. Res., 51, 576-598, https://doi.org/ 10.1002/2014WR015740.

— W. Li, L. Zeng, and L. Wu, 2016: An adaptive Gaussian process-based method for efficient Bayesian experimental design in groundwater contaminant source identification problems. Water Resour. Res., 52, 5971-5984, https://doi.org/ 10.1002/2016WR018598.

Zhang, J. L., Y. Li, G. Huang, C. Wang, and G. Cheng, 2016: Evaluation of uncertainties in input data and parameters of a hydrological model using a Bayesian framework: A case study of a snowmelt-precipitation-driven watershed. J. Hydrometeor., 17, 2333-2350, https://doi.org/10.1175/JHM-D-15-0236.1.

Zhang, Y., and Coauthors, 2007: Study on snowmelt runoff simulation in the Kaidu River basin. Sci. China. Ser. D Earth Sci., 50, 26-35, https://doi.org/10.1007/s11430-007-5007-4.

Zhao, R., 1992: The Xinanjiang model applied in China. J. Hydrol., 135, 371-381, https://doi.org/10.1016/0022-1694(92)90096-E. 